\title{
A CLÍNICA DO AUTISMO SOB UMA PERSPECTIVA DESENVOLVIMENTISTA: O PAPEL DO ENGAJAMENTO AFETIVO NO DESENVOLVIMENTO DA COMUNICAÇÃO E DA LINGUAGEM
}

Este trabalho teve como referencial a perspectiva desenvolvimentista, segundo a qual o engajamento afetivo é fundamental para o desenvolvimento da comunicação humana. Seu objetivo foi a implementação de um programa de intervenção clínica para o autismo que teve como base o trabalho com a música. A realização deste objetivo compreendeu duas partes: uma teórica e a pesquisa de campo. Esta última consistiu na aplicação do programa a uma criança autista, na avaliação se o programa proporcionou ou não o desenvolvimento do engajamento afetivo e da comunicação na criança bem como se houve uma relação entre estes aspectos.

\section{BANCA:}

Carolina Lampreia (Orientadora)

Flavia Sollero de Campos

Renata Mousinho Pereira da Silva

Data da defesa: 05/03/2009 